\title{
Estudo da relação entre experiência e inovação na cultura contemporânea
}

\author{
Estudio de la relación entre experiência e innovación em la cultura \\ contemporânea
}

\author{
Study of the relationship beteween experience and innovation in \\ contemporary culture
}

\author{
Denise de Sena Pinho ${ }^{1}$ \\ Maurivan Güntzel Ramos ${ }^{2}$
}

\begin{abstract}
Resumo
As relações interpessoais na Educação a Distância (EaD) configuram-se como um sistema complexo, o qual depende de uma dinâmica de funcionamento e manifestações comportamentais dos sujeitos envolvidos. Este trabalho aborda as possibilidades de compartilhamento de experiências no ciberespaço, em processos de constituição de práticas educativas online. Este estudo se insere em uma pesquisa, que culminará em uma tese de doutorado pelo Programa de Pós-Graduação em Educação em Ciências e Matemática da Pontifícia Universidade Católica do Rio Grande do Sul - PUCRS. Neste artigo apresenta-se a análise dos diálogos estabelecidos em fórum online. Como pressupostos, o artigo apresenta o entendimento sobre Educação Matemática com foco na formação continuada a distância de professores. Numa abordagem qualitativa de pesquisa e análise das informações pelo método Análise Textual Discursiva (ATD). O Objetivo identificar e analisar as principais experiências docentes relatadas pelos participantes dos fóruns online em um curso a distância de especialização para professores de Matemática Nesse sentido, destaca-se a constituição do ambiente em EaD com elementos técnicos e principalmente humanos e o conjunto de relações que se estabelecem no ciberespaço com a identidade e um contexto específico disponibilizado com a intenção clara de aprendizagem. Entre as categorias que emergiram da questão, tem-se à inovação como princípio cultural na contemporaneidade para uma Educação Matemática de qualidade.
\end{abstract}

Palavras-Chave: Ciberespaço; Cultura Contemporânea; Educação a Distância; Experiência; Inovação.

\section{Resumen}

Las relaciones interpersonales en la Educación a Distancia (EaD) se configuran como un sistema complejo, el cual depende de una dinámica de funcionamiento y manifestaciones comportamentales de los sujetos involucrados. Este trabajo aborda las posibilidades de compartir experiencias en el ciberespacio, en procesos de constitución de prácticas educativas en línea. Este estudio se inserta en una investigación, que culminará en una tesis de doctorado por el Programa de Postgrado en Educación en Ciencias y Matemáticas de la Pontificia Universidad Católica de Rio Grande do Sul - PUCRS. En este artículo se presenta el análisis de los diálogos establecidos en un foro en línea. Como suposiciones, el artículo presenta el entendimiento sobre Educación Matemática con foco en la formación continuada a distancia de profesores. En un abordaje cualitativo de investigación y análisis de las informaciones por el método Análisis textual Discursivo (ATD). El objetivo de identificar y analizar las principales experiencias docentes relatadas por los participantes de los foros en línea en un curso a distancia de especialización para profesores de matemáticas. En este sentido, se destaca la

\footnotetext{
${ }^{1}$ Mestre em Educação em Ciências e Matemática; Pontifícia Universidade Católica do Rio Grande do Sul PUCRS; Porto Alegre, RS, Brasil; denise.pinho@acad.pucrs.br

${ }^{2}$ Doutor em Educação; Pontifícia Universidade Católica do Rio Grande do Sul - PUCRS; Porto Alegre, RS, Brasil; mgramos@pucrs.br.
} 
constitución del ambiente en $\mathrm{EaD}$ con elementos técnicos y principalmente humanos y el conjunto de relaciones que se establecen en el ciberespacio con la identidad y un contexto específico puesto a disposición con la intención clara de aprendizaje. Entre las categorías que surgieron de la cuestión, se tiene a la innovación como principio cultural en la contemporaneidad para una Educación Matemática de calidad.

Palabras clave: Ciberespacio; Cultura Contemporánea; Educación a Distancia; La experiencia; La innovación

\begin{abstract}
Interpersonal relations in distance education $(\mathrm{EaD})$ are configured as a complex system, which depends on a functioning dynamics and behavioral manifestations of the subjects involved. This paper discusses the possibilities of sharing experiences in cyberspace, in the processes of constitution of online educational practices. This study is part of a research that will culminate in a PhD thesis by the Graduate Program in Science and Mathematics Education of the Pontifical Catholic University of Rio Grande do Sul - PUCRS. This article presents the analysis of the dialogues established in an online forum. As assumptions, the article presents an understanding about Mathematics Education focusing on the continuous distance learning of teachers qualitative approach to research and analysis of information by the Textual Discursive Analysis (ATD) method. . In a The objective is to identify and analyze the main teaching experiences reported by online forum participants in a distance learning specialization course for Mathematics teachers. In this sense, we highlight the constitution of the environment in EaD with technical elements and mainly human and the set of relationships that establish in the cyberspace with the identity and a specific context made available with the clear intention of learning. Among the categories that emerged from the question, one has to innovation as a cultural principle in the contemporaneity for a Mathematical Education of quality.
\end{abstract}

Key words: Cyberspace; Contemporary Culture; Distance Education; Experience; Innovation

\title{
1. Introdução
}

A Educação a Distância (EaD) é uma possibilidade para a democratização do acesso ao conhecimento, pois minimiza algumas barreiras de espaço/tempo da educação presencial, desde aquelas causadas pelo isolamento e distanciamento geográfico das grandes cidades, onde se concentram os centros formadores, até as questões de horários pré-definidos das aulas presenciais. Além disso, outras variáveis, tais como, o insuficiente número de vagas, a incompatibilidade de horários e a impossibilidade de muitos estudantes conciliarem trabalho com estudo, reforçam a necessidade da oferta de formação mediada pela web.

Com o advento das tecnologias digitais, via rede mundial, vivenciamos a potencialidade de diversos modos de comunicação. A informação virtualiza-se, constituindo a " marca registrada do ciberespaço”. (Lévy 1999, p. 92). Nesse sentido é possível disponibilizar cursos na modalidade $\mathrm{EaD}$, em especial, de pós-graduação. Essas ofertas vêm se constituindo como propostas para ampliação da formação continuada de professores, contemplando regiões distantes dos centros universitários. O movimento na cultura contemporânea, de aprendizagem, nos remete a seguinte concepção de EAD:

A EAD explora certas técnicas de ensino a distância, incluindo as hipermídias, as redes de comunicação interativas e todas as tecnologias intelectuais da cibercultura. Mas o essencial se encontra em um novo estilo de pedagogia, que favorece ao mesmo tempo as aprendizagens personalizadas e a aprendizagem coletiva em rede (LÉVY, 2005, p. 158) 
Dito isso, o presente estudo buscou identificar e analisar as principais experiências docentes relatadas pelos participantes dos fóruns online em um curso a distância de especialização para professores de Matemática. O diálogo ocorreu no Ambiente Virtual de Aprendizagem (AVA) institucional, Moodle, no qual foram utilizados os fóruns como ferramenta de interlocução. Metodologicamente, optou-se pela pesquisa qualitativa, na qual o pensamento qualitativo é considerado "interpretativo, baseado em experiências, situacional e humanístico" (STAKE, 2011, p. 41). O trabalho do pesquisador é realizado de forma imersiva nas escritas dos participantes da pesquisa. As informações coletadas foram analisadas por meio da Análise Textual Discursiva (MORAES; GALIAZZI, 2007).

Portanto, é necessário ir além da possibilidade de romper com as barreiras geográficas. Necessita-se o incentivo de espaços virtuais potencializados pela experiência dos participantes. O contexto da pesquisa ocorreu em um Curso de Especialização a Distância para Professores de Matemática em uma universidade da rede pública federal de ensino, localizada na região ao sul do Brasil.

Inicialmente apresenta-se o referencial teórico que dá sustentação a análise e aos argumentos do texto. Após, pontua-se entendimentos sobre educação online, $\mathrm{EaD}$ e formação continuada de professores na perspectiva dos saberes docentes. Na sequência são expostos os procedimentos metodológicos da investigação, apresentando a abordagem qualitativa da pesquisa, como também o modo de análise das informações, por meio da ATD. Na seção seguinte, abordam-se compreensões sobre os saberes da docência que emergiram da análise da investigação, bem como, a discussão entrelaçada com o referencial teórico. Finaliza-se o artigo com algumas considerações sobre o estudo realizado.

\section{A Educação a Distância ou Educação online na cultura contemporânea}

A utilização das tecnologias digitais de comunicação ampliou as possiblidades dos contextos de aprendizagem na cultura contemporânea. Com suporte na web, a mídia passa a contar com os benefícios da comunicação mediatizada online. Entende-se educação online como:

Conjunto de ações de ensino e de aprendizagem ou atos de currículo mediados por interfaces digitais que potencializam práticas comunicacionais interativas e hipertextuais [...] para a democratização da informação, da comunicação e da aprendizagem entre indivíduos geometricamente dispersos. (SANTOS, 2010, p. 37).

A disseminação das tecnologias digitais e da internet promoveram atualizações nas maneiras de comunicação, e a modalidade $\mathrm{EaD}$ se amplia pela superação de distâncias ao 
possibilitar maior interatividade e promover o advento da Educação Online (EO). Para que a $\mathrm{EaD}$ se torne efetivamente EO, necessita-se atentar para, pelo menos, três enfoques essenciais: atuação dos sujeitos intervindo nas mensagens de forma colaborativa; diálogos nos quais ocorrem a produção conjunta dos sujeitos e a liberdade de trocas em múltiplas redes articuladas (SILVA, 2006).

Portanto, ao utilizar tecnologias digitais da web, pode-se ter uma multiplicidade de interfaces para promover discussões síncronas e assíncronas. Os diálogos síncronos ocorrem de forma imediata, isto é, os sujeitos que participam de uma conversa estão conectados online, por rede, e utilizam ferramentas digitais, como por exemplo, chats e webconferência, que permitem registrar e acompanhar todas as comunicações que estejam ocorrendo. Os diálogos assíncronos são aqueles em que os sujeitos se comunicam, a qualquer tempo, sem a necessidade de todos estarem interligados em rede, sendo exemplos, os fóruns, e-mails dos grupos e blogs.

Embora a EO nos revele ferramentas potenciais para prática da $\mathrm{EaD}$ via web, ainda vivemos as limitações da largura de banda dos sinais de transmissão, o que impede, em muitos casos, a utilização de mídias de áudio, vídeos e comunicações. Tais limitações tecnológicas têm impedido que se supere a $\mathrm{EaD}$ e se avance para uma $\mathrm{EO}$, na perspectiva apontada por Silva (2006).

Dessa forma, a opção por comunicações assíncronas, como os fóruns de discussão, além de permitir a interação online, possibilita o envio e leitura das mensagens, com maior flexibilidade em relação à quando fazê-lo, isto é, ocorre num modo de diálogo atemporal. Silva (2006) afirma que em interatividade assíncrona é possível que ocorram debates relacionados a temas instigadores, com provocações, participações e posicionamentos em relação ao que é proposto.

Diante das considerações acima, entende-se que ofertas de cursos de formação continuada para professores de Matemática, podem ser efetivados com suportes nas inovações relevantes, tanto na $\mathrm{EaD}$, quanto na $\mathrm{EO}$, possibilitando intensas reflexões sobre a educação como um todo. Considera-se que nesse viés o foco está em utilizar as tecnologias para produzir um crescente de interlocuções sobre os temas fomentados entre esses professores em formação tanto on quanto off-line.

\section{Experiência na relação com formação continuada}

A temática formação continuada vem sendo pesquisada nos últimos vinte anos, com discussões relacionadas à problematização da profissionalização docente. Iniciadas na década 
de oitenta, as múltiplas pesquisas foram subsidiadas por teorias e diversidades de métodos, sendo propostas várias concepções a respeito do saber dos professores (TARDIF, 2010). No Brasil, as referências teóricas foram embasadas nos estudos de Gauthier (2006), Tardif (2010) e Schuman (2005), entre outros. Pode-se identificar nas pesquisas desses autores, a experiência como tema relevante e interligado com outras proposições de seus estudos.

Na perspectiva de Gauthier (2006) a forma plural do saber docente, coexiste na relação entre os saberes docentes. Nesse interesse, destaca-se ser "mais pertinente conceber o ensino como mobilização de vários saberes que formam uma espécie de reservatório no qual o professor se abastece para responder a exigências específicas de sua situação concreta de ensino" (GAUTHIER, 2006, p.28). Os saberes definidos pelo autor são: disciplinares, curriculares, das ciências da educação, da tradição pedagógica, experienciais e da ação pedagógica.

Nos saberes experienciais, o autor considera o desenvolvimento da aprendizagem da profissão como algo solitário, ocorrendo de forma individual. Outro ponto considerado se refere a novas temáticas para reflexão, considerando as experiências realizadas na prática profissional. As escritas do autor, nos traz as experiências vivenciadas pelos professores como não comunicáveis. Existe um distanciamento desses saberes experienciais com a formação profissional.

Quer se trate de um momento único ou repetido infinitas vezes, a experiência do professor não deixa de ser uma coisa pessoal e, acima de tudo, privada. Embora o professor viva muitas experiências das quais tira grande proveito, tais experiências, infelizmente, permanecem confinadas ao segredo da sala de aula. Ele realiza julgamentos privados, elaborando ao longo do tempo uma espécie de jurisprudência composta de truques, de estratagemas e de maneiras de fazer que, apesar de testadas, permanecem em segredo. Seu julgamento e as razões nas quais ele se baseia nunca são conhecidos nem testados publicamente (GAUTHIER, 2006, p.33).

Outros estudos apontam os saberes profissionais, num cenário com base nas "realidades sociais, organizacionais e humanas, nas quais os professores se encontram mergulhados" (TARDIF, 2010, p. 11). Para esse autor, o conhecimento pode ser profissional provém da formação inicial e continuada dos professores, conhecimento das disciplinas ministradas, das experiências do dia a dia, dos discursos e das ações; sendo, portanto, definido pelo saber social do qual fazem parte, e cujos saberes são refletidos na maneira de como eles ensinam.

Tais saberes são expressos em um saber compartilhado pelos atores, além dos conhecimentos práticos que estão enraizados em razões, motivos e interpretações. O autor propõe a existência de quatro saberes interligados: os saberes da formação profissional; os 
saberes disciplinares; os saberes curriculares e os saberes experienciais. Segundo Tardif (2010), a ligação dos professores com esses saberes se dá por diversos meios.

As instituições de formação de professores são contextos propícios para junção dessas ciências com a prática docente. Ainda assim, existe uma fronteira entre teorias, pesquisas e a atuação no meio escolar, tendo como consequência um afastamento entre os "produtores do saber" e os "executores ou técnicos" (TARDIF, 2010).

Segundo Tardif (2010), no mesmo ambiente escolar os professores, na prática da profissionalização em sala de aula, no seu trabalho diário e conhecendo o meio em que estão inseridos, desenvolvem os saberes oriundos tanto da experiência individual quanto coletiva, com seus pares (estudantes, professores, equipe diretiva e comunidade escolar como um todo). Esses saberes podem ser chamados de saberes experienciais ou práticos.

Diferentemente da expressão saberes docentes utilizada por Tardif (2010) e Gauthier (2006), Shulman (2005) nomeia três categorias de conhecimentos: do conteúdo específico, do pedagógico e do curricular. Tais categorias servem de instrumentos fundamentais para pesquisas dos processos de desenvolvimento cognitivo profissional docente.

Convém ressaltar que uma concepção de formação que compreenda um conjunto possível de formas de interação e cooperação entre professores da universidade, tutores, professores da Educação Básica e comunidade escolar, foi o caminho delineado na estruturação do Curso de Formação Continuada de Professores de Matemática, foco da abordagem deste artigo.

\section{Procedimentos metodológicos}

O delineamento do estudo está sistematizado no campo de uma pesquisa qualitativa, em que o pesquisador mantém contato direto com o ambiente e os participantes. Nesse sentido o pensamento qualitativo é considerado "interpretativo, baseado em experiências, situacional e humanístico" (STAKE, 2011, p. 41). O trabalho do pesquisador é realizado de imersiva nas escritas dos participantes da pesquisa. Adota-se uma postura da hermenêutica filosófica, possibilitando reconstruções de compreensões, num contínuo fluxo de leitura e interpretação (GADAMER, 2002). Nesse sentido, o estudo desenvolveu-se com as configurações descritas a seguir.

A investigação foi realizada em um dos cinco polos de apoio presencial no qual foi ofertado o Curso de Especialização para Professores de Matemática em uma universidade pública do sul do país. Como um dos critérios de escolha dos participantes da pesquisa adotamos "professores de Matemática em exercício". Desse modo, participaram desta 
investigação vinte e um professores em formação. Para manter o anonimato dos participantes da pesquisa, os professores em formação serão designados pela palavra Participante, seguida de uma letra maiúscula, por exemplo: Participante A.

Considerou-se como investigação a rede de conversação formada por esses professores, que participaram ativamente do fórum realizado no AVA, na disciplina ministrada por um dos autores deste artigo. O corpus da investigação foi, portanto, constituído pela transcrição dos diálogos representativos ocorridos entre os professores em formação, ao pensarem e conversarem sobre seus saberes profissionais e sua prática em sala de aula.

Iniciou-se a pesquisa pelas conversações em torno das questões propostas para serem discutidas no fórum, como por exemplo, a solicitação: "Vamos dialogar sobre saberes profissionais, a relação com a sua prática e suas experiências”. Para análise das escritas no fórum, usamos a Análise Textual Discursiva (MORAES; GALIAZZI, 2007). O corpus utilizado foram as escritas dialógicas realizadas nos fóruns online. Como primeira parte da análise, ocorreu a desmontagem desses textos escritos pelos professores em formação. Esse momento, de intensa imersão nas informações, denomina-se unitarização. Decorrente disso, num processo de desconstrução e reconstrução das perspectivas elencadas pelos professores em formação sobre a temática discutida, definiu-se as unidades de significado.

O segundo momento, da análise deu-se com o estabelecimento das relações. A fase de agrupamento das unidades de significado a partir das relações, denomina-se de categorização. Agrupa-se as unidades de significado considerando as aproximações e distanciamentos percebidos nas escritas pelos participantes da pesquisa, originando, assim 12 categorias iniciais, que, por reagrupamentos sucessivos, deu origem a duas categorias finais

Captando o novo emergente, refere-se à terceira parte da análise, o que resulta em metatextos elaborados a partir de duas categorias finais. Nesse momento, o processo de produção configura-se como um movimento descritivo e interpretativo que emerge das reconstruções acerca do fenômeno estudado, a partir do levantamento de questionamentos e compreensões das falas dos professores em formação e do estabelecimento do diálogo com os teóricos (MORAES; GALIAZZI, 2007). É esse movimento que possibilita a compreensão das expressões dos participantes da pesquisa, a respeito dos seus saberes profissionais e possibilita atingir compreensões do que os professores em formação manifestam, no fórum de discussão online, em relação aos seus saberes profissionais.

\section{Descrição e análise das informações}


Com a realização da leitura e da análise das informações produzidas nos fóruns online, chegamos a três categorias finais sempre considerando os elementos presentes no objetivo pesquisa. Esse texto buscou identificar e analisar as principais experiências docentes relatadas pelos participantes dos fóruns online em um curso a distância de especialização para professores de Matemática, produzidos em um curso de Especialização a distância para professores nessa área.

Diante disso, tem-se a terceira fase da análise. Nessa fase, comunica-se novas compreensões que emergiram ao longo das duas fases anteriores. Elaborou-se para cada categoria final um metatexto inicial com a explicitação das categorias intermediárias e das relações entre elas, descrevendo os novos insights e teorizações que emergiram por autoorganização. Esse processo, decorreu de uma impregnação intensa com os dados e informações do corpus analisado, nesse momento, também ocorreu a interlocução teórica.

Muitas são as experiências relatadas entre os professores em formação. Dentre essas, na categoria intermediária Experiência como saberes além do espaço educativo destacamos as experiências compartilhadas, o olhar de outras possibilidades até então, não valorizadas, a pluralidade de saberes e a importância desses saberes.

Com o propósito de formação de professores que fuja do isolamento profissional, é pontuado pelos professores em formação, de forma a contemplar o " saber interativo, mobilizado e modelado no âmbito das interações" (TARDIF, 2014, p. 109). A partir da escrita: "Acredito que as discussões nos fóruns, a colaboração e compartilhamento de experiências e saberes proporcionado pelos colegas e professores poderão contribuir para meu desenvolvimento profissional e pessoal." (PARTICIPANTE F), é possível, percebermos a atitude de compartilhar, desses professores. Essa atitude, surge como fomento aos modos de integração dos saberes docentes com o trabalho docente.

Nota-se, nas discussões sobre os temas em debate, dos professores em formação, que esses almejam um processo de mudança, no qual está o Repensar e reinventar os saberes docentes. Tal inquietação, sobre o repensar e reinventar, é percebida na escrita: "Que proporcione novas técnicas e novas possibilidades para cada vez mais, despertar em meus alunos o interesse e as possibilidades inseridas no saber e no conhecimento matemático" (PARTICIPANTE K). Essa necessidade é apontada como superação dos processos conservadores na educação.

Todo esse movimentado constitutivo do refletir e repensar saberes docentes, é pontuado por diversas variáveis, entre elas temos algumas fontes de aquisição de saberes. Essas formas de aquisições de saberes, situam-se nas histórias de vida, nas experiências 
vividas na escola pelos professores em formação, nas atividades, nos cursos de formação continuada, nos livros didáticos e nas experiências interativas que mobilizam novos olhares, conforme Tardif (2014).

A Inovação é compreendida como intenção de ruptura com processos educacionais conservadores. Nesse sentido as pesquisas em educação matemática mostram-se promissoras, como argumenta o professor em formação: "As pesquisas podem dar um norte importante para que cada professor possa inovar em suas práticas de mediação da aprendizagem e tornar tudo mais atrativo para que o aluno tenha curiosidade e veja sentido em aprender". (Participante A). A escrita do professor em formação evidencia uma sua posição enquanto mediador da aprendizagem, contudo acredita a inovação como algo novo e ainda não realizado no contexto escolar. De acordo Cunha (2008), a ruptura com modelos tradici0oais de ensinar e aprender, não significa desconsiderar as contribuições das ciências, mas reconhecer “ $[\ldots]$ outras formas de produção de saberes, incorporando a dimensão sóciohistórica do conhecimento e sua dimensão axiológica que une sujeito e objeto". (CUNHA, 2008, p.24).

Assim, como destaca as discussões nos fóruns online para que aconteça a ruptura com os processos educacionais vigentes se faz necessário realizar mudanças com consciência e participação coletiva. A professora em formação aponta um dos movimentos necessários para efetivação de inovação como ruptura de ações educativas, salienta que "é importante a saída da zona de conforto, tanto de professores quanto de alunos, bem como o fomento da vontade fazer diferente, de indagar, de buscar". (PARTICIPANTE H). Nessa perspectiva, são consideradas primeiramente a dimensão de afetividade e conhecimento em relação a mediação do professor, possibilitando um respeito mútuo entre educando e educador. Após, observamos a preocupação com o fazer diferente, a necessidade da pergunta e a curiosidade como impulso para buscar algo a mais, ou novo. As dimensões podem ser pensadas no coletivo, por todos atores do processo educacional, como é descrito na maioria das falas dos professores em formação

Com as reconfigurações dos saberes, pontua-se as escritas que relatam a transformação da realidade como a intenção de inovar A intencionalidade para inovação: transformar a realidade. Observa-se por meio das interlocuções realizadas a preocupação com ruptura de paradigmas da ciência moderna.

Se essa se sustentava na classificação e na dicotomização dos seres e dos saberes, o que se propõem como novo é o abandono das estratificações dualistas entre saber científico/saber popular, ciência/ cultura, educação/trabalho, corpo/alma, teoria/prática, ciências naturais/ciências sociais, objetividade/subjetividade, 
arte/ciência, ensino/pesquisa e tantas outras formas propostas para a compreensão dos fenômenos humanos. (CUNHA, 2008, p. 25).

As mudanças destacadas, incluem a experiência da realidade como ponto a ser considerado, quando afirmam ser fundamental aproximação com a totalidade. O novo considera as formas de saberes populares, extrapola dimensões conservadoras.

\section{Conclusões}

Para identificar e analisar as principais experiências docentes relatadas pelos participantes dos fóruns online em um curso a distância de especialização para professores de Os professores em formação ou participantes da pesquisa, como foram nomeados, relataram a formação continuada como reconstrução de seus saberes, na convivência interativa e social, nas experiências em sala de aula e/ou outros contextos, com os pares e evidenciaram a relação entre discurso teórico e atividades em sala de aula.

Portanto, podemos afirmar que para esse grupo de professores em formação, os diferentes momentos e situações em sala de aula, ressignificaram os saberes necessários a profissionalização, tendo na coletividade um ambiente propicio para aprender com o outro. Argumentos como relações de afeto e formação da identidade do professor foram relatadas como dimensão ética ligada a convivência com os estudantes. Outra percepção destacada é o fato do professor aprender com a experiência, considerando seus alunos.

Com a ressignificação entre discurso teórico e atividades em sala de aula, a relação teoria e prática se manifestou como representação de uma teoria como estado pronto e acabado, em contrapartida com a prática como algo construído, em constante movimento. Entretanto, alguns professores em formação pontuaram a necessidade dos saberes do conteúdo num processo de aperfeiçoamento e conexões com a atividade em sala de aula. No ciberespaço onde aconteceu o curso, foi possível perceber nos diálogos e necessidade do novo, talvez no sentido de inovação, mas precisa-se considerar o sentido da experiência com a profissionalização.

As evidências apontadas nos revelam a preocupação dos professores em formação com suas elaborações e reconstruções diárias para uma melhor qualidade da sua profissionalização, bem como, a interlocução com os diferentes saberes. Haja vista que, os diferentes olhares sobre os alunos e as relações pedagógicas ampliam possibilidades de uma educação mais humanizada e de qualidade.

Assim, identificamos a necessidade de oferta de cursos de formação continuada que atenda às necessidades dos professores em formação, num ciclo dialético, considerando as experiências por eles vividas. Nesse sentido reiteramos a necessidade de pesquisas que 
tenham como objeto de análise, os saberes interligados com as experiências dos professores em formação. Dessa forma, podemos contribuir com a qualificação do processo formativo de professores.

\section{Referências}

CUNHA, Antônio Eugenio. Afeto e Aprendizagem, relação de amorosidade e saber na prática pedagógica. Rio de Janeiro. Wak. 2008.

GADAMER, Hans-Georg. Verdade e método: traços fundamentais de uma hermenêutica filosófica; Tradução Flávio Paulo Meurer. 4 ed. Petrópolis: Vozes, 2002.

GAUTHIER, Clermont et al. Por uma teoria da pedagogia: pesquisas contemporâneas sobre o saber docente. $2^{\mathrm{a}}$ ed. Ijuí: Editora Unijuí, 2006.

LÉVY, Pierre. Cibercultura. São Paulo: 34, 1999.

. O que é virtual? São Paulo: Ed.34, 2005

MORAES, Roque; GALIAZZI, Maria do Carmo. Análise textual discursiva. Ijuí: Ed. Unijuí, 2007.

SANTOS, M. Por uma outra globalização: do pensamento único à consciência universal. Rio de Janeiro: Record. 19. ed., 2010.

SILVA, Marco (Org.). Educação online. São Paulo: Loyola, 2006.

SILVA, Marco (Org.). Educação on-line :teorias, práticas, legislação e formação corporativa Edição Loyola. 2. Ed. São Paulo. 2006.

STAKE, Robert. Pesquisa qualitativa: estudando como as coisas funcionam. (Karla Reis Trad.). Porto Alegre: Penso, 2011.

SHULMAN, Lee S. Conocimiento y enseñanza: fundamentos de la nueva reforma. Profesorado. Revista de Currículum y Formación de Profesorado. v.9, n.2, Granada, España, 2005.

TARDIF, Maurice. Saberes docentes e formação profissional. $4^{\text {a }}$ Ed. Rio de Janeiro: Vozes, 2010.

TARDIF, Maurice; LESSARD, Claude. $O$ trabalho docente: elementos para uma teoria da docência como profissão de interações humanas. Tradução de João Batista Kreuch. 13 ${ }^{\mathrm{a}}$ edição. Petrópolis: Vozes, 2007 